\title{
Quasi-monolithic planar load cells using built-in resonant strain gauges
}

\section{Harrie A C Tilmans and Miko Elwenspoek}

MESA Research Institute, University of Twente, PO Box 217, 7500 AE Enschede, The Netheriands

\begin{abstract}
Two load cell designs are presented using resonant strain gauges providing a frequency output. One design is based on a four-point beam deflection jig. It offers high sensitivity, but suffers from robustness and impractical geometries for a broad force range. A modified planar design (typical dimensions $1-10 \mathrm{~mm}$ ) removes these drawbacks and in addition features built-in force reduction, overload protection and compensation of common mode effects. Load ranges vary from high $(1500 \mathrm{~N})$ to very low $(0.03 \mathrm{~N})$, with theoretically achievable resolutions as high a 1 part in $10^{7}$.
\end{abstract}

\section{Introduction}

A load cell is a transducer that produces an output proportional to an applied force [1-3]. Load cells are applied in industrial and technical fields and in chemical and medical laboratories, for instance as sensitive weighing cells [1-4]. The strain-gauge-based load cell is the major force measuring technique applied today. In such a cell, an elastic spring member bears the applied force and produces a strain field that is sensed by the strain gauge(s) and converted into an electric output signal that is proportional to the force. Foiltype resistance strain gauges are the best characterized and most widely types [1]. The high costs of cementing the foil-type strain gauges to the spring element and the problems that result with creep have led to the development of thin film $[1,5]$ and thick film $[6,7]$ and semiconductor (integrated) [8] strain gauges.

This paper deals with strain-gauge-based load celss, whereby the integrated (piezo)resistance strain gauges are replaced by built-in resonant strain gauges [912]. The main feature of the cell is the frequency output, which allows easy digital interfacing, provides inherent accuracy, and means a lower susceptibility to electrical interference and degradation of transmitted signals. The main goal of this research is to investigate the feasibility of such a load cell with respect to compactness, ruggedness and a high performance-tocost ratio. Two different designs are described. One design is based on a four-point beam deflection jig and the other is a planar design featuring built-in force reduction, overload protection and compensation of common mode effects. Micromachining of silicon is proposed as the fabrication technology, allowing costeffective planar designs. In this paper, only a few performance issues will be addressed. Main focus will be on the theoretically achievable resolution as a function of geometry and load range. Performance aspects that will not extensively be dealt with, are accuracy, linearity, creep behaviour, hysteresis, repeatability, conformance and drift. These factors will eventually determine the overall performance of the load cell. In this context it is noted that resolution designates only the number of digits in the readout, without making a statement about the accuracy of the last digit [2]. In order to minimize creep and hysteresis, non-integral connections must be avoided calling for a monolithic or integral structure. This is illustrated by the second design.

\section{Four-point bending beam load cell}

The design of the four-point bending beam load cell is based on the structure described in [13]. A cross section is shown in figure 1(a). The cell consists of a sensor beam, with a resonant strain gauge in the middle, and a jig, consisting of a load bar and a pedestal. The jig is used to transmit the applied force $F$ to the sensor beam. The beam is supported by knife edges as shown. It is evident that the resonator must be located between the inner knife edges. A force-frequency measurement of a silicon micromachined structure [10] in the range $0-60 \mathrm{gf}$ is shown in figure 1(b). The fundamental frequency is close to $444 \mathrm{kHz}$ and the sensitivity is $1.22 \mathrm{kHz} \mathrm{gf}^{-1}$. A short-term frequency stability of $10 \mathrm{ppm}$, i.e., a stability of $4.4 \mathrm{~Hz}$, results in a force resolution of $3.6 \mathrm{mgf}$. The measured temperature coefficient of the strain gauge is $-135 \mathrm{ppm} /{ }^{\circ} \mathrm{C}$. This demands a temperature stability better than $0.07^{\circ} \mathrm{C}$ in order to achieve the aforementioned resolution.

\subsection{Load response-resolution}

The following (realistic) assumptions are made: the load bar, pedestal and the force are properly aligned, 
Table 1. Predicted resolution of the four-point beam load cell of figure 1 for several force ranges and geometries. Fixed parameters are as follows: $E_{\mathrm{s}}=169 \mathrm{GPa}, \epsilon_{Y}=0.5 \%\left(\sigma_{\mathrm{Y}}=E_{\mathrm{s}} \epsilon_{\mathrm{Y}}\right),(\Delta f / f)_{\mathrm{s}, \min }=10^{-5}, L=1 \mathrm{~mm}$ and $G_{\varepsilon}=$ $2000 ; y_{\max }$ denotes the maximum deflection at full scale input.

\begin{tabular}{|c|c|c|c|c|c|c|c|c|c|c|}
\hline \# & $\begin{array}{l}\text { Range } \\
F_{\max }(\mathrm{N})\end{array}$ & $\begin{array}{l}b_{s} \\
(\mathrm{~mm})\end{array}$ & $\begin{array}{l}h_{\mathrm{s}} \\
(\mu \mathrm{m})\end{array}$ & $\begin{array}{l}a_{\max } \\
(m m)\end{array}$ & $\begin{array}{l}a \\
(\mathrm{~mm})\end{array}$ & $\begin{array}{l}\Delta F_{\min } \\
(\mathrm{mN})\end{array}$ & $\begin{array}{l}\text { Resolution } \\
\text { (ppmFS) }\end{array}$ & $\begin{array}{l}y_{\max } \\
(\mathrm{mm})\end{array}$ & Practical & Comments \\
\hline $\begin{array}{l}1 \\
2 \\
3 \\
4 \\
5 \\
6\end{array}$ & $\begin{array}{l}10 \\
1.500 \\
1.500 \\
0.03 \\
0.03 \\
0.03\end{array}$ & $\begin{array}{r}3 \\
3 \\
10 \\
3 \\
3 \\
3\end{array}$ & $\begin{array}{r}380 \\
380 \\
2000 \\
380 \\
380 \\
12\end{array}$ & $\begin{array}{c}12.2 \\
0.08 \\
7.5 \\
4000 \\
4000 \\
8.1\end{array}$ & $\begin{array}{c}5.0 \\
0.08 \\
5.0 \\
4000 \\
4.0 \\
4.0\end{array}$ & $\begin{array}{l}0.024 \\
1.5 \\
2.25 \\
3 \times 10^{-5} \\
0.03 \\
3 \times 10^{-6}\end{array}$ & $\begin{array}{c}2.4 \\
1.0 \\
1.5 \\
1.0 \\
1000 \\
1.0\end{array}$ & $\begin{array}{l}0.12 \\
0.004 \\
0.04 \\
1.4 \times 10^{5} \\
0.0002 \\
6.1\end{array}$ & $\begin{array}{l}y \\
n \\
y / n \\
n \\
y \\
n\end{array}$ & $\begin{array}{l}\text { - } \\
\text { Difficult to align } \\
\text { Large thickness } \\
\text { Very large size } \\
\text { Low resolution } \\
\text { Very fragile }\end{array}$ \\
\hline
\end{tabular}

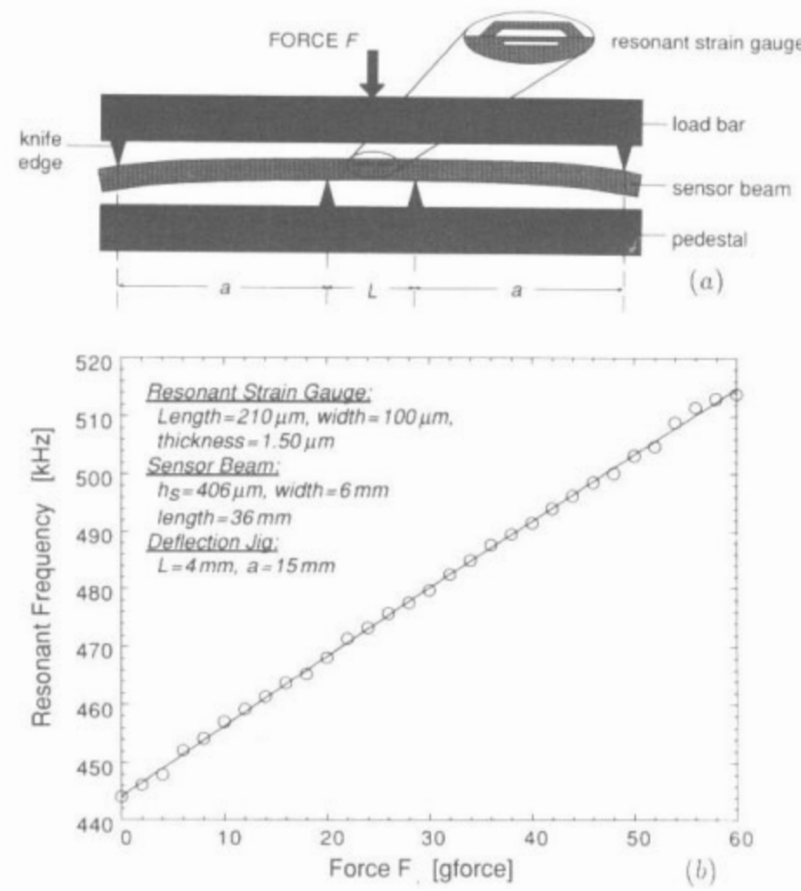

Figure 1. (a) Cross-sectional view of the four-point bending beam load cell. (b) Measured resonant frequency versus the applied force of the load cell with dimensions as indicated. The solid line indicates a least square second-order polynomial fit, indicating a terminal-based non-linearity of $1 \%$ Fso. The resonant strain gauge is a doubly-clamped vacuum encapsulated electrostatically driven polysilicon beam [10]. The sensor beam is cleaved from a silicon wafer.

the load bar and pedestal are rigid, the sensor beam is prismatic with a rectangular cross section (width $b_{\mathrm{s}}$ and thickness $h_{\mathrm{s}}$ ), there is no friction between the knife edges and the sensor beam, the material behavior is linearly elastic and the contribution of the stiffness of the resonant strain gauge to the overall stiffness of the sensor beam is neglected. From elementary strength of materials it can now easily be derived that the section of the sensor beam between the inner knife edges is subjected to a uniform bending moment $M_{\mathrm{F}}=\frac{1}{2} F a$, leading to a bending strain in the fibres. The bending strain is experienced as an axial strain by the resonator which is located in the upper fibres (i.e., moment arm is $\frac{1}{2} h_{\mathrm{s}}$ ). This causes a shift of the resonant frequency $f_{\text {res }}$ of the gauge. The sensitivity of the resonant frequency to the axial strain $\epsilon$ is described by the gauge factor $G_{\epsilon} \equiv\left(1 / f_{\text {res }}\right)\left(\mathrm{d} f_{\mathrm{res}} / \mathrm{d} \epsilon\right)$ [9]. A measure for the sensitivity of the four-point bending beam load cell to the applied force $F$ is given by the gauge factor $G_{\mathrm{F}} \equiv\left(1 / f_{\text {res }}\right)\left(\mathrm{d} f_{\text {res }} / \mathrm{d} F\right)$. The force resolution $\Delta F_{\text {min }}$ of the load cell can now be expressed as [9]:

$$
\begin{gathered}
\Delta F_{\min }=(\Delta f / f)_{S, \min } / G_{\mathrm{F}} \approx(\Delta f / f)_{S, \min } \\
\quad /\left[\left(3 a / E_{\mathrm{s}} b_{\mathrm{s}} h_{\mathrm{s}}^{2}\right) G_{\epsilon}\right]
\end{gathered}
$$

where $(\Delta f / f)_{S, \min }$ denotes the short-term frequency stability [9], $a$ is the arm length as indicated in figure 1(a) and $E_{\mathrm{s}}$ denotes the Young's modulus of the sensor beam material. The ultimate force range $E_{\text {ult }}$ is determined by the ultimate stress $\sigma_{\mathrm{Y}}$ (or strain $\epsilon_{\mathrm{Y}}$ ) (e.g., the yield stress or fracture stress) of the structure. It is easily derived that,

$$
F_{\mathrm{ult}}=\left(E_{\mathrm{s}} b_{\mathrm{s}} h_{\mathrm{s}}^{2} / 3 a\right) \epsilon_{\mathrm{Y}}=\left(b_{\mathrm{s}} h_{\mathrm{s}}^{2} / 3 a\right) \sigma_{\mathrm{Y}}
$$

and using (1),

$$
\Delta F_{\mathrm{ult}} / F_{\mathrm{ult}}=(\Delta f / f)_{S, \min } / \epsilon_{\mathbf{Y}} G_{t} .
$$

Equation (3) gives the best achievable resolution $\Delta F_{\text {ut }}$ as a fraction of $F_{\text {ult }}$. The above equations clearly indicate that for an optimum resolution, $(\Delta f / f)_{S, \min }$ must be a small as possible, whereas $\epsilon_{\mathrm{Y}}$ and $G_{\epsilon}$ must be as high as possible. Using rather conservative parameters, $(\Delta f / f)_{S, \min }=10^{-5}, G_{\epsilon}=10^{3}$ and $\epsilon_{\mathbf{Y}}$ $=10^{-3}$, yield a resolution of 1 part in $10^{5}$. Resolutions better than 1 part in $10^{7}$ can theoretically be achieved. Also note the trade-off indicated by (3) between force range and resolution. By increasing the resolution, the force range is decreased.

Besides the attainable resolution, the final dimensions and compactness of the load cell are also of practical importance. For a given force range $F_{\max }$, the following geometrical constraint must be satisfied in order to prevent yielding or fracturing of the structure:

$$
\begin{aligned}
\epsilon_{\max } & <\epsilon_{\mathrm{Y}} \Rightarrow F_{\max }<F_{\mathrm{ult}} \\
& \Rightarrow b_{\mathrm{s}} h_{\mathrm{s}}^{2} / a>3 F_{\max } / \sigma_{\mathrm{Y}}
\end{aligned}
$$

where $\epsilon_{\max }$ denotes the maximum induced strain. For a given $b_{\mathrm{s}}, h_{\mathrm{s}}, F_{\max }$ and $\sigma_{\mathrm{Y}}$, the length $a$ should not exceed a maximum value, designated as $a_{\max }$. It is 
evident that the maximum attainable force resolution is achieved for $a=a_{\max }$. Examples of several load cell designs with predicted resolutions, based on the foregoing theory, are given in table 1 .

The lack of robustness, the limited practical range, as illustrated by the examples of table 1 , and the absence of compensation for unwanted shifts due to temperature or other external loads, call for improvements. An example of an improved design is presented in the next section.

\section{Quasl-monollthic planar load cell}

Figure 2(a) shows a sketch of the central part of a quasi-monolithic planar load cell. A packaged device is shown in figure 2(b). For more details about the packaging, reference is made to Yoshida and Tanigawa [8]. A planar design is employed which is attractive from a fabrication point of view [3]. Silicon micromachining techniques are preferably used to fabricate the pedestal, the load bar and the sensor beam; the three pieces are then bonded together. The resonators are builtin, meaning that their fabrication process is integrated with the process of the sensor beam [10-12]. The cell features built-in overload protection, built-in force reduction and built-in temperature compensation. The latter is based on a differential resonator design [14].

\subsection{Force reduction}

The external load $W$ is applied to the load bar (figure 2(a)). The load bar is rigidly bonded to the sensor beam at three places as indicated in the figure. The force $F$ being transmitted to the sensor beam is always smaller than $W$, thus providing a means of force reduction. A similar approach has been suggested for a resonant diaphragm force sensor [15]. An expression for the force reduction $\Lambda$, defined as the ratio of the force $F$ and the force $W$, is easily derived by noting that the center displacements of the boss of the load bar and of the sensor beam are the same (and ignoring in-plane stress stiffening):

$$
\left.\Lambda \equiv F / W=1 /\left[1+\left(l_{\mathrm{s}}\right) / l_{\mathrm{c}}\right) /\left(h_{\mathrm{s}} / h_{\mathrm{c}}\right)^{3} E_{\mathrm{c}} b_{\mathrm{c}} / E_{\mathrm{s}} b_{\mathrm{s}}\right]
$$

where $l_{\mathrm{c}}, l_{\mathrm{s}}, h_{\mathrm{c}}, h_{\mathrm{s}}$ are as indicated in figure $2(\mathrm{a}), E_{\mathrm{c}}$ and $E_{\mathrm{s}}$, are the Young's modulus of the material of the load bar and the sensor beam, respectively, and $b_{c}$, and $b_{\mathrm{s}}$, are the width of the load bar and sensor beam, respectively. Note that $\Lambda$ is always smaller than unity. The most suitable parameters to adjust $\Lambda$ are $l_{\mathrm{c}}, l_{\mathrm{s}}$, $h_{c}$ and $h_{8}$, since the Young's moduli and widths are usually very close in magnitude. Practical ranges for the geometrical parameters are: $0.1<l_{\mathrm{s}} / l_{\mathrm{c}}<1$ and $0.01<h_{s} / h_{\mathrm{c}}<1$. This allows force reductions in the range: $10^{-6}<\Lambda<1$ (assuming $E_{\mathrm{c}}=E_{\mathrm{s}}$ and $b_{\mathrm{c}}=b_{\mathrm{s}}$ ). In practice this means that a given sensor beam can be used in combination with several load bar designs in order to accommodate the desired force range.
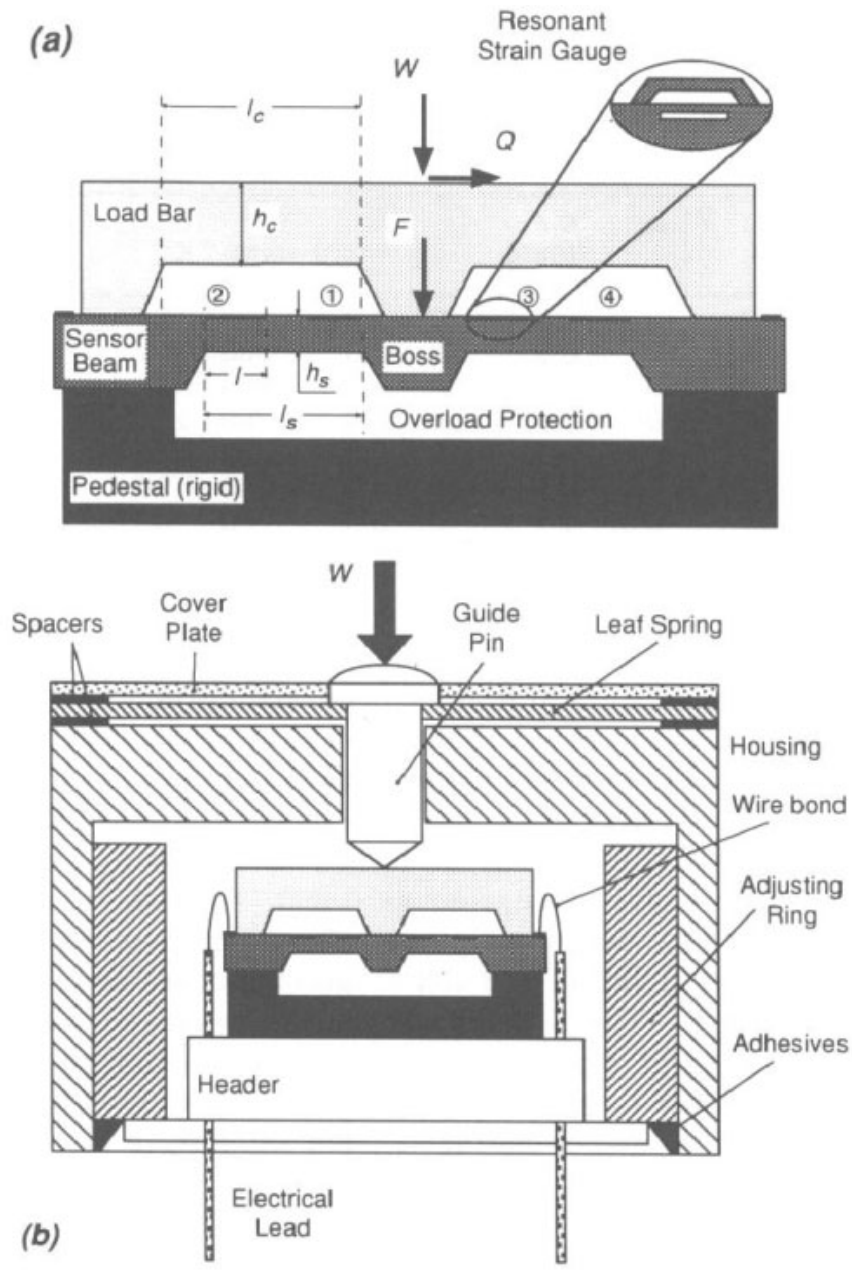

Figure 2 (a) Quasi-monolithic planar load cell showing the sensor beam, sandwiched between a load bar and a pedestal. The resonators are labelled 1,2,3 and 4. (b) Packaged device according to Yoshida and Tanigawa [8]

\subsection{Load response-resolution}

In order to facilitate the mathematics and to allow a straightforward comparison with the four-point beam load cell, the load response will first be derived for a single resonator output. Considerations of a differential output will be discussed at the end of this section. Similar assumptions and symbols are used as for the four-point beam cell described in section 2. The force resolution $\Delta W_{\min }$ of the load cell, obtained from either one of the resonators in figure 2(a), can be expressed as:

$$
\begin{gathered}
\Delta W_{\min }=(\Delta f / f)_{s_{1, \min }} / G_{\mathrm{W}} \approx(\Delta f / f)_{s, \min } \\
\quad /\left\{\frac{3}{2}\left[\left(l_{\mathrm{s}}-l\right) / E_{\mathrm{s}} b_{\mathrm{s}} h_{\mathrm{s}}^{2}\right] \Lambda G_{\epsilon}\right\}
\end{gathered}
$$

where $G_{\mathrm{W}} \equiv\left(l / f_{\mathrm{res}}\right)\left(\mathbf{d} f_{\mathrm{res}} / \mathrm{d} W\right)=G_{\mathrm{F}} / \Lambda$ and $l$ denotes the resonator length. For a given force range $W_{\max }$, the following condition must be satisfied in order to prevent yielding or fracturing:

$$
\begin{aligned}
\epsilon_{\max } & <\min \left(\epsilon_{\mathrm{Y}^{\prime}} \epsilon_{\mathrm{Y}_{\mathrm{c}}}\right) \Rightarrow W_{\max }<W_{\mathrm{ult}} \\
& =\min \left(\frac{1}{1-\Lambda} \frac{2 b_{\mathrm{s}} h_{\mathrm{s}}^{2} E_{\mathrm{s}}}{3 l_{\mathrm{s}}} \epsilon_{\mathrm{Ys}^{\prime}} \frac{1}{\Lambda} \frac{2 b_{\mathrm{c}} h_{\mathrm{c}}^{2} E_{\mathrm{c}}}{3 l_{\mathrm{c}}} \epsilon_{\mathrm{Y}_{\mathrm{c}}}\right)
\end{aligned}
$$


Table 2. Example designs of the load cell in figure 2 for: $\epsilon_{Y s}=\epsilon_{Y_{c}}=0.5 \%, E_{s}=E_{c}=169 \mathrm{GPa},(\Delta f / f)_{s \text {,min }}$ $=10^{-5}, l=0.2 \mathrm{~mm}, b_{c}=b_{s}=3 \mathrm{~mm}$ and $G_{c}=2000 ; \%$-ult indicates $W_{\max }$ as a fraction of $W_{\text {ult, }}(7)$. The pressure stop gives an indication of the distance of the stopping surface to keep the maximum strains below $\epsilon_{Y s}$ and $\epsilon_{Y e}$.

\begin{tabular}{|c|c|c|c|c|c|c|c|c|c|c|c|c|}
\hline \# & $\begin{array}{l}W_{\max } \\
(N)\end{array}$ & $\begin{array}{l}I_{\mathrm{s}} \\
(\mathrm{mm})\end{array}$ & $\begin{array}{l}h_{\mathrm{s}} \\
(\mu \mathrm{m})\end{array}$ & $\begin{array}{l}I_{c} \\
(\mathrm{~mm})\end{array}$ & $\begin{array}{l}h_{c} \\
(\mu \mathrm{m})\end{array}$ & $\Lambda$ & $\begin{array}{l}F_{\max } \\
(N)\end{array}$ & $\begin{array}{l}\Delta W_{\min } \\
(\mathrm{mN})\end{array}$ & $\begin{array}{l}\text { Res. } \\
\text { (ppmFS) }\end{array}$ & $\begin{array}{l}y_{\max } \\
(\mu \mathrm{m})\end{array}$ & $\begin{array}{l}\% \text {-ult } \\
(\%)\end{array}$ & $\begin{array}{l}\text { Pressure } \\
\text { stop }(\mu \mathrm{m})\end{array}$ \\
\hline $\begin{array}{r}7 \\
8 \\
9 \\
10 \\
11 \\
12 \\
13\end{array}$ & $\begin{array}{c}10 \\
10 \\
1500 \\
1500 \\
0.03 \\
0.03 \\
0.03\end{array}$ & $\begin{array}{l}0.6 \\
0.6 \\
0.6 \\
0.6 \\
0.6 \\
0.6 \\
1.0\end{array}$ & $\begin{array}{r}50 \\
30 \\
50 \\
380 \\
30 \\
10 \\
15\end{array}$ & $\begin{array}{l}1.0 \\
2.0 \\
1.0 \\
1.0 \\
2.0 \\
5.0 \\
5.0\end{array}$ & $\begin{array}{r}75 \\
380 \\
1000 \\
760 \\
50 \\
30 \\
0\end{array}$ & $\begin{array}{l}0.58 \\
0.02 \\
5.8 \times 10^{-4} \\
0.11 \\
0.89 \\
0.96 \\
1.00\end{array}$ & $\begin{array}{c}5.78 \\
0.18 \\
0.87 \\
167.0 \\
0.03 \\
0.03 \\
0.03\end{array}$ & $\begin{array}{l}0.018 \\
0.21 \\
18.3 \\
5.50 \\
0.004 \\
4.4 \times 10^{-4} \\
4.8 \times 10^{-4}\end{array}$ & $\begin{array}{r}1.8 \\
21.2 \\
12.2 \\
3.7 \\
143 \\
14.7 \\
15.8\end{array}$ & $\begin{array}{l}9.9 \\
1.4 \\
1.5 \\
0.7 \\
0.2 \\
6.1 \\
8.8\end{array}$ & $\begin{array}{r}82.0 \\
8.0 \\
89.0 \\
82.0 \\
1.1 \\
10.2 \\
7.9\end{array}$ & $\begin{array}{c}12 \\
17 \\
1.7 \\
0.8 \\
19 \\
60 \\
110\end{array}$ \\
\hline
\end{tabular}

where min denotes the minimum function, $\epsilon_{\max }$ denotes the maximum induced strain, and $\epsilon_{Y_{s}}$ and $\epsilon_{Y_{c}}$ denote the ultimate (or maximum allowable) strain for the sensor beam and the load bar, respectively.

Table 2 gives examples of compact designs for three force ranges. The maximum deflection $y_{\max }$ at full scale input is kept smaller than $h_{\mathrm{c}}$ and $h_{\mathrm{s}}$ to suppress large deflection effects. The examples indicate a great flexibility of the cell to accommodate several force ranges. This is the big advantage compared with the four-point bending beam load cell of section 2 . The best way to improve the resolution is by lowering $(\Delta f / f)_{S, \min }$ and/or raising $G_{\epsilon}$. For instance, if $G_{\varepsilon}=$ 5000 and $(\Delta f / f)_{S, \min }=10^{-7}$ the indicated resolutions are improved by a factor 250 . For the $0.03 \mathrm{~N}$ cell this means resolutions better than $10^{-7}$, which compares favourably with the best ultramicro weighing scales available today [4]. Choosing smaller widths $b_{\mathrm{s}}$ and $b_{\mathrm{c}}$ will also improve the resolution, but at the same time, $y_{\max }$ will increase and $W_{\text {ut }}$ will decrease. Materials with a higher $\epsilon_{\mathrm{Y}_{s}}$ and $\epsilon_{\mathrm{Yc}}$ will extend the range of allowable dimensions and thus can be used to improve the resolution. Table 2 also indicates that pushing the limits (i.e., $W_{\max }$ approaches $W_{\text {utt }}$ ) leads to a better resolution.

\subsection{Compensation of error sources}

The theory and examples given above are all based on the frequency output of either one of the four resonators of the structure in figure 2. The structure accommodates two differential pairs of resonators located on either side of the boss. It is expected that the performance of such a multi-resonator structure will be superior compared with the single-resonator structure. It is beyond the scope of this paper to go into detail regarding this topic, but a few aspects are indicated below. A difference frequency output allows compensation of unwanted common loads such as temperature and humidity [14]. In effect, the infuence of unwanted loads is reflected in the short term frequency stability [9]. Other error sources in a load cell are the eccentricity $e$ of the applied load and the existence of shear forces $Q$ (see figure 2). A nonzero eccentricity causes rotation of the boss leading to a disturbance of the induced strain field. It is evident that larger in-plane dimensions of the boss will lower the effect of an eccentric load. Moreover, it can be argued that the rotation and thus the eccentricity can be extracted from the frequencies of all four resonators. For $e=0$, the resonant frequencies of the individual resonators are given by: $f_{i}=f_{0} \pm \Delta f_{\mathrm{W}} \pm \Delta f_{\mathrm{Q}}+\Delta f_{\mathrm{T}}$, where a subscript $i$ indicates the resonator, $f_{0}$ denotes the unloaded resonant frequency and $\Delta f_{\mathrm{w}}, \Delta f_{\mathrm{Q}}$ and $\Delta f_{T}$ denote the frequency shifts due to the applied force $W$, a shear force $Q$ and a common load, e.g. temperature, respectively. It is easily derived that $\Delta f_{\mathrm{Q}}$ can be found from the frequency difference of resonators 2 and 4: $f_{2}-f_{4}=2 \Delta f_{\mathrm{Q}}$ and furthermore, $f_{2}+f_{3}=2 \Delta f_{\mathrm{T}}$ and $f_{2}-f_{1}=f_{4}-f_{3}=2 \Delta f_{\mathrm{W}}$.

\section{Conclusions}

This paper has demonstrated the feasibility of specific micromachining load cells using resonant strain gauges. A novel planar design, covering a broad force range, has been presented. It offers built-in force reduction, overload protection and compensation of error sources. Based upon a theoretical model, force resolutions are predicted of 1 part in $10^{5}$ and with some effort of 1 part in $10^{7}$. Although these figures are very promising, the proposed load cell is still far from being declared practical. The actual performance of the load cells must be determined in a real environment, whereby a wide range of determining factors must be considered.

\section{Acknowledgments}

This research was supported by the Dutch Technology Foundation (STW). Hans Schurer is acknowledged for doing the measurements presented in figure $1(\mathrm{~b})$.

\section{References}

[1] Erdem U 1982 Force and weight measurement $J$. Phys. E. Sci. Instrum. 15 857-72

[2] Zulliger H R 1983 Precise measurement of small forces Sens. Actuators 4 483-95 
[3] Bethe K 1991 Dynamometrical sensors: (many) problems, (some) solutions Sens. Actuators A 25-27 285-93

[4] Berg C 1990 Laborwaagen Nachr. Chem. Tech. Lab. 38 M1-M9

[5] Bethe K and Schön D 1980 Thin-film strain-gauge transducers Philips Tech. Rev. 39 94-101

[6] Puers B, Sansen W and Paszczynski S 1987 Assessment of thick-film fabrication methods for force (pressure) sensors Sens. Actuators 12 57-76

[7] White N M and Brignell E 1991 A planar thick film load cell Sens. Actuators A 25-27 313-9

[8] Yoshida K-I and Tanigawa H 1989 Development of a force sensor for minute load measurement IEEE/CHMT '89 Japan IEMT Symp. (Japan, 1989) pp 201-4

[9] Tilmans $\mathrm{H}$ A C, Elwenspoek $\mathrm{M}$ and Fluitman J H J 1992 Micro resonant force gauges Sens. Actuators A 30 35-53

[10] Tilmans H A C 1993 Micromechanical Sensors Using Encapsulated Built-in Resonant Strain Gauges PhD Thesis University of Twente, Enschede, The Netherlands ISBN 90-9005746-3
[11] Sniegowski J J, Guckel H and Christenson T R 1990 Performance characteristics of second generation polysilicon resonating beam force transducers Proc. IEEE Solid-State Sensors and Actuators Workshop (Hilton Head Island, SC, 1990) pp 9-12

[12] Nikolich A D and Senturia S D 1992 A wafer-bonded silicon load cell operating in the tensioned-wire regime Proc. IEEE Solid-State Sensors and Actuators Workshop (Hilton Head Lsland, SC, 1992) pp 157-60

[13] Bouwstra S, de Weerd E and Elwenspoek M 1990 In-situ phosphorus-doped polysilicon for excitation and detection of micromechanical resonators Sens. Actuators $24227-35$

[14] Tilmans H A C, Bouwstra S, Jntema D J I, Elwenspoek M and Klein C F 1991 A differential resonator design using a bossed structure for applications in mechanical sensing Sens. Actuators 26 385-93

[15] Smits J G and Huizing B 1983 A resonant diaphragm applied as a force sensor Internal Report, Univensity of Twente kenmerk 1222.3843 pp 24-7 (in Dutch) 